\title{
CORRESPONDENCIA DE ANTONIO MAURA CON EMILIA PARDO BAZÁN, SOFÍA CASANOVA Y CONCHA ESPINA
}

\author{
MARÍA DEL CARMEN SimÓN PALMER \\ $(\text { CSIC })^{1}$
}

\section{RESUMEN}

Don Antonio Maura mantuvo correspondencia con tres renombradas escritoras desde el año 1901 hasta el de su fallecimiento en 1925: Emilia Pardo Bazán, Sofía Casanova y Concha Espina. El apoyo que les prestó, como miembro y luego director de la Real Academia Española, para la concesión de diversos premios, su firma al frente de las candidaturas al Nobel de Sofía Casanova y Concha Espina y su opinión favorable a la entrada de mujeres en la Academia lo descubren como una excepción en su tiempo.

Palabras clave: Antonio Maura Montaner, Emilia Pardo Bazán, Sofía Casanova, Concha Espina, Epistolario, Premios Literarios, Real Academia Española.

\section{ANTONIO MAURA'S CORRESPONDENCE WITH EMILIA PARDO BAZÁN, SOFÍA CASANOVA AND CONCHA ESPINA}

\section{ABSTRACT}

Don Antonio Maura held correspondence with three renowned women writers from 1901 until he died in 1925: Emilia Pardo Bazán, Sofía Casanova y Concha Espina. The way he supported them - once as a member of the Royal Spanish Language Academy and later as Director - for the award of various prizes, his signature for Sofía Casanova's and Concha Espina's candidature for the Nobel prize and his favourable opinion about women gaining admittance to the Academy reveal him as an exception in those days.

Key words: Antonio Maura Montaner, Emilia Pardo Bazán, Sofía Casanova, Concha Espina, correspondence, literary prizes, Royal Spanish Language Academy.

\section{Correspondencia de Antonio Maura con Emilia Pardo Bazán, Sofía CASANOVA Y CONCHA ESPINA}

Pocos fueron los intelectuales que, ya en los inicios del siglo XX, reconocieron a las mujeres una capacidad semejante a la suya, tanto para la creación

\footnotetext{
${ }^{1}$ Este trabajo se encuadra dentro del proyecto del MEC (HUM2007-63608). Agradezco las facilidades prestadas por el director de la Fundación Maura. Don Alfonso Pérez Maura de la Peña y la archivera D. ${ }^{a}$ Carmen Rivera.
} 
literaria como para ocupar puestos de responsabilidad. Sobresale en este aspecto Antonio Maura Montaner que no se recató, por ejemplo, en hacer pública su postura favorable a la entrada de escritoras en la Academia, si bien con algunos matices, y que encabezó la candidatura al premio Nobel de Sofía Casanova y Concha Espina.

La posición privilegiada de Maura en la sociedad en esos años, por una parte como Presidente de Gobierno y por otra como Académico de la Española primero y más tarde su director, le convirtió en un centro de atracción a la hora de solicitar favores.

La correspondencia personal que mantiene con tres escritoras famosas como Emilia Pardo Bazán, Sofía Casanova y Concha Espina, le muestra como un ejemplo de diplomacia ante las peticiones variadas que recibe de ellas: entrevistas, premios, recomendaciones, etc.

Las estrategias empleadas por las autoras para ganar su apoyo tienen puntos en común pero difieren de acuerdo con su posición social.

\section{Cartas de EMilia PARdo BaZÁn ${ }^{2}$}

La correspondencia entre Antonio Maura y Emilia Pardo Bazán demuestra una confianza que transciende lo formal, de modo que doña Emilia no repara en pedirle favores de todo tipo con lo que, en ocasiones, le pone en verdaderos apuros. Sus cartas son, en principio, políticas, pasa luego a buscar directamente su apoyo como académico y, por último, impulsada por el deseo de promocionar a su hijo y a su yerno, retorna a la política.

La primera noticia está fechada en el mes de julio de 1901 y, como sucederá a menudo, es para solicitar recomendación para un conocido, pero llega tarde (Carta 1). Tiene entonces el pretexto para, tras agradecerle la gestión, confesarle su afinidad ideológica y animarle para que tome las riendas del partido liberal y sustituya a Silvela, para lo que utiliza en su razonamiento lo que ella denomina un «apólogo» (2).

Ese mismo año se despide antes de su viaje a Francia, Bélgica y Holanda, a los que califica como «país [sic], adelantado, católico y feliz», y promete tenerle al tanto de sus impresiones. Desde allí, doña Emilia enviará sus crónicas a El Imparcial, en las que muestra su admiración por Bélgica con un catolicismo «militante y civilizador». Le da noticia del Discurso pronunciado en los Juegos Florales de Orense el mes anterior sobre los males de la Patria en el que defiende el derecho de la mujer a preocuparse por la situación política y procurar su remedio (3).

En varias tarjetas se interesa por la salud del cuñado de Maura, Germán Gamazo, que fallece ese mismo año de 1901 (4). Ya en 1906 le pide, un tan-

\footnotetext{
${ }^{2}$ FUNDACIÓN MAURA. Fondo Antonio Maura Montaner. Legajo 81/33.
} 
to misteriosamente, entrevistarse con su hijo para no molestarle a él. Maliciosamente se ofrece a recibirle en el Congreso donde su presidente «nuestro amigo Dato», rival dentro del partido de Maura: «ha puesto a mi disposición un despacho».

En septiembre de 1907, se celebra en La Coruña el homenaje a Concepción Arenal, presidido por Pardo Bazán en el que participaron Azcárate, Marchesi, Salillas y García Ramos, y donde ella en su discurso hizo un alegato feminista con recuerdos de su infancia y un elogio de la vida y obra de Arenal (8). Sin embargo, siente la necesidad de justificarse ante don Antonio. Existe la idea de que ambas escritoras, parientes lejanas, no habían congeniado excesivamente en vida entre otras cosas porque su personalidad era muy distinta. Y si atendemos a la reacción que había tenido Concepción Arenal ante la petición de Lázaro Galdiano de datos biográficos para anticiparse a un libro que sobre ella pensaba escribir Pardo Bazán, no parece equivocada la idea $^{3}$.

El año 1907 Maura vuelve a la Presidencia, en el llamado Gobierno largo, hasta noviembre de 1909, en que se producen los sucesos de Barcelona y la Semana trágica, que desembocó en el fusilamiento de Ferrer Guardia y en una campaña contra él y su gobierno. Faltan cartas de doña Emilia en esos momentos de desaliento pero se compensan con las incondicionales de su hijo, Jaime Quiroga, escritas desde Nador y que llenan de satisfacción a don Antonio (9).

Se suceden las peticiones de recomendación los años siguientes, sin que aquí nos interesen, pero en el 1912 la revista Nuevo Mundo publica una encuesta sobre la posibilidad de que ella entre en la Academia ${ }^{4}$ y Pardo Bazán escribe a Maura y al tiempo que le llena de elogios, aprovecha su respuesta favorable para pedirle, el 10 de abril de 1912, que la presente, puesto que también Galdós la apoya con su firma (10).

Es sabido que ella misma se dirige al director de la Academia, que era entonces don Alejandro Pidal, con una instancia autógrafa en la que solicita ser designada para una de las dos vacantes que quedaban desde el mes de marzo de 1912, y la acompaña de su currículo y numerosos telegramas de personalidades de Galicia. La Academia recurrió al acuerdo de 1853, cuando pretendió lo mismo Gertrudis Gómez de Avellaneda ${ }^{5}$.

${ }^{3}$... «Soy de la opinión que no deben hacerse biografías de las personas vivas, y nunca he querido proporcionar datos para la mía, de modo que el dárselas a $\mathrm{Vd}$. sería no solo inconsecuencia en mí, sino descortesía respecto a las personas á quien los negué...» ( 9 de mayo de 1892) en SIMÓN PALMER, María del Carmen. Arenal y Lázaro. La admiración por una mujer de talento (1889-1895) Madrid: Fundación Lázaro Galdiano, Ollero y Ramos, 2002, p. 62.

4 «Indagatoria Literaria: ¿Será académica la Pardo Bazán?». Nuevo Mundo, 4 de abril de 1912.

${ }^{5}$ ZAMORA VICENTE, Alonso. Historia de la Real Academia Española. Madrid: Espasa Calpe, 1999, p. 493. 
Las dos plazas se cubrieron con Ricardo León y Augusto González Besada. El 3 de diciembre de 1912, su hijo, Jaime Quiroga, desde la Torre de Meirás agradece al duque el pésame por la muerte de su padre ${ }^{6}$ : «En estos dolorosísimos momentos y después de la resignación cristiana, las simpatías de nuestros amigos son el único lenitivo a nuestra pena, más aún cuando provienen de quien, como V., tiene sobre nosotros toda la justísima influencia de su talento y de su posición». De paso le comenta que ha quedado huérfano de influencia conservadora el distrito de Santa María de Órdenes donde su pariente, el marqués de Figueroa, cuenta con un numeroso grupo de curas párrocos que pueden apoyarle si lleva él la representación del partido para lo que pide a Maura su beneplácito.

Doña Emilia insiste en su deseo de ser académica y de nuevo escribe al duque el 20 de octubre de 1913, aunque comienza por pedirle recomendación para que asciendan a su yerno, el coronel Cavalcanti, y le manifiesta su deseo de que Maura presida la Academia, algo que ocurre poco después, en sustitución, tras su fallecimiento, de Alejandro Pidal y Mon.

En los años siguientes doña Emilia va a continuar pidiéndole recomendaciones de todo tipo y denuncia algunas situaciones de política local gallega que considera injustas para lo que no duda en solicitar a Maura que intervenga cerca del Tribunal Supremo (1915).

En 1920 le felicita por su nombramiento como Caballero de la Orden del Toisón de Oro y las últimas noticias son de 1921, poco antes de su fallecimiento.

\section{1}

Sr. Don Antonio Maura

La Coruña 27-6-1901

Mi ilustre amigo: ¿Puede hacer V. algo en lo que expresan las adjuntas notas? Espera respuesta su amiga y admiradora:

Emilia Pardo Bazán.

(Nota borrador del duque escrita sobre el original): «Cuando recibí su apreciable ya se nos había puesto a despacho el expediente del recomendado de V. sin que me fuese posible modificar un acuerdo que estimé justo, por lo que resultaba de las diligencias instruidas.

Crea V. que siento verme privado de contestarle en mejores términos y como lo habría deseado su afmo». 3 de julio.

\footnotetext{
${ }^{6}$ Don José Quiroga fallece en Carballino y la condesa, a pesar de su separación va a guardar luto como demuestran sus cartas orladas de negro.
} 
La Coruña/ Torres de Meirás

12 de julio de 1901

Don Antonio Maura

Mi querido amigo: Con la carta tan amable y tan indulgente que ha tenido V. la bondad de dirigirme me da V. alas para decirle algo que está hace tiempo en el pensamiento, pero que no me parecía discreto formular sin algún precedente como el que por fortuna mía ya me sirve de estímulo.

Hace tres años le dije a Silvela: «La ocasión que para todos tiene un pelito, para V. por circunstancias especiales ha echado una mata soberbia de pelo rubio y ondeante. Si no la agarra $\mathrm{V}$. mal año».

Creo inútil añadir lo que sucedió: La mano de Silvela, o cansada o inerte no se cerró sobre la hermosa cabellera, flota en el espacio, apartando la mano, no de nieve sino vigorosa y grande, que la agarre y no la suelte mas.

Algo sola se va quedando a fuerza de flotar en el vacío; sin embargo, todavía es tiempo. Por qué no es V. el que la ase? Está V. en edad propicia, tiene condiciones para ser el hombre de España, dentro del partido liberal que poco tardaría en disolverse y reorganizarse. Medítelo V. y acuérdese de que Sócrates tuvo que sacrificar un gallo, a veces hay que sacrificar... el sacrificio mismo han solido valer una misa y también el ir a misa... solo los días de fiesta.

Dispénseme V. si esto le parece una sencillez de persona agena a la política maliciosa y reserve para si mi apólogo de la cabellera, y créame pero de verdad su admiradora y amiga auténtica q.b.s.m.

Emilia Pardo Bazán ${ }^{7}$

3

(Tarjeta postal) Don Antonio Maura/ Diputado. Santander (Sardinero)

La Coruña 25 julio 1901

Con el pie en el estribo para París y Bélgica, las gracias y promesa de escribirle desde allá lo que me sugiera el espectáculo de un país católico y adelantado y feliz ${ }^{8}$.

\footnotetext{
${ }^{7}$ En lo que se refiere a tan comentada posición política de doña Emilia es interesante lo que ella misma comenta en su reseña a la Bibliotheque Espàgnole de Boris de Tannenberg, publicada en La Lectura, (1-X-1903), sobre su filiación carlista inicial y ahora «en el partido de los más avanzados reformadores», según el autor: «...no me es indiferente la política, ¡no! en lo que importa a España, pero la desprecio en su bajo revuelo de personalismos, todos y agradándome infinito el trato de los políticos y disfrutando el de muchos, de los cuales la susodicha leyenda me ha puesto por turnos partidaria, conservo la independencia mas orejana ¡Que afán de encasillar a la gente!».

${ }^{8}$ Un año más tarde publicaría sus impresiones en Por la Europa Católica. Madrid: Tip. Idamor Moreno, 1902. 272 pp.
} 
Leído discurso en edición Español ${ }^{9}$

Por siempre amiga y admiradora

Pardo Bazán

\section{4}

(Carta con orla de luto) Torres de Meiras/Betanzos. Sada) 4-10-901

Sr. Don Antonio Maura

Mi ilustre amigo:

Felicito a V. cordialmente por la mejoría de don Germán ${ }^{10}$ que deseo tan constante y duradera como Vds. la desearán, para tranquilidad de su espíritu.

Siempre de V. buena amiga

Emilia Pardo Bazán

\section{5}

(Carta con orla de luto)

Sr. Don Antonio Maura

La Coruña 2-12-901

Mi muy distinguido amigo: Con mucho sentimiento he visto que la enfermedad de don Germán terminó como temíamos. Lo presentía porque era de las que no perdonan.

Reciba V. mi pésame: entristece que vayan despareciendo todos los que sobresalían del nivel de su generación y no parece sino que algún Tarquesio se entretuviese en blandir el látigo y descabezar a España.

Sabe V. que en esta ocasión como en todas su sincera amiga q.b.s.m.

Emilia Pardo Bazán

\section{6}

(Tarjeta postal sin fecha con grabado de la fachada de las Torres de Meiras dirigida a D. Antonio Maura, Lealtad 18)

14 junio. Mil felicidades en la octava de San Antonio.

La condesa de Pardo Bazán

\footnotetext{
${ }^{9}$ Se refiere al de A. MAURA. Discurso pronunciado en los Juegos Florales de Orense la noche del 2 de junio de 1901. Temas: Los males de la Patria. Coruña: Imp. de la Casa de Misericordia. 1901. 40 pp.

10 Germán Gamazo (1840-1901) abogado, político y cuñado de Antonio Maura.. 
(Tarjeta con corona grabada)

Lunes [s.a. 4-IV-1906]

Mi ilustre amigo: Necesito hablar con V. breves momentos antes de que empiece la dispersión.

Si su hijo Gabriel ${ }^{11}$ siempre tan amable estuviese aquí se encargaría se transmitirle lo que tengo que decirle pues sé que se encuentra en Londres.

Desearía molestar a V lo menos y por eso le ruego día y hora que sea lo mas fácil en la Presidencia ¿tal vez en el Congreso, donde nuestro amigo Dato ha puesto a mi disposición un despacho, y algunas veces he ido a hablar con señores diputados? Esto, por evitar a V. la pérdida de tiempo tan precioso. Si $\mathrm{V}$. dispone de un momento, yo tengo todos los míos a disposición de V. Puede $\mathrm{V}$. ordenar que me indiquen por teléfono lo que V. guste. Y perdón, y gracias, de su amiga muy verdadera.

La Condesa de Pardo Bazán

4. IV. 06

(Nota del Duque): «Como mi hijo Gabriel está en Madrid, a él he dado traslado de lo que manifiesta en su atenta de ayer, para que se ponga por completo a sus órdenes.

Aunque sea por teléfono, estos a su casa de V, quiero evitar toda confusión con estos renglones, de no proporcionar también el gusto de repetirme suyo afmo».

\section{8}

La Coruña $1^{\text {o }}$ sept. 1907 (con corona)

Excmo. Sr. D. Antonio Maura

Mi ilustre amigo: Llamo a V. la atención hacia el discurso que le envío, en la velada en honor a D. ${ }^{a}$ Concepción Arenal.

Mejor dicho: hacia los párrafos señalados. Porque no pretendo que V. haya de leerlo entero. Conozco sus quehaceres.

Esta velada se hizo un poco para ponerme en compromiso y apuro. Yo desdeño esas miserias y he tenido gusto en tributar homenaje a doña Concepción Arenal. Pero se ha tratado de evitar que la velada revistiese cierto carácter y de dar la nota que creí necesaria, al par que justa, pues todo lo que dijo está bien atado en los escritos mismos, y no en fantasías.

\footnotetext{
${ }^{11}$ Gabriel Maura Gamazo (1879-1963) En este año ya era Diputado por el Partido Conservador.
} 
Soy de V. insigne amiga y apasionada

Emilia Pardo Bazán.

(Nota-borrador del Conde 5 de sept.) «Mi ilustre amiga: Me apresuro a agradecer a V. el envío de su discurso en el homenaje organizado para conmemorar la ilustre vida de $\mathrm{D}^{\mathrm{a}}$ Concepción Arenal. Cualquier paréntesis de mis ocupaciones ásperas y muy encadenadas estos días, he de utilizarlo en la lectura de esa página donde ya de antemano puede afirmarse que lo atinado del juicio tendrá siempre el realce de una insuperable perfección literaria.

De V. siempre afmo. amigo...»

Nador, 25-X-1909 ${ }^{12}$

Entre los innumerables testimonios de admiración, respeto y adhesión que V. habrá recibido a estas horas, sírvase contar con el de un soldado de España que hoy, por primera vez, y al saber la noticia de la crisis, ha dejado de sentirse lleno de aliento. ¡Dios salve a España, que empezaba a volver a ser lo que ha sido! Consérvese V. pues su vida es nuestra última esperanza y mande como guste al Cabo de Húsares de la Princesa.

Jaime Quiroga Pardo Bazán.

(Nota-borrador del duque) «Con viva complacencia recibo su carta fechada en Nador, y con gratitud acojo las amables frases que me consagra. Son ellas doblemente gratas por venir de quien como V. prueba en dura campaña su amor a la patria y por estar dictadas entre riesgos y preocupaciones que avaloran altamente el recuerdo. Le desea salud y gloria y muy afmo. amigo

Excmo. Sr. Don Antonio Maura

10-4-1912

Ilustre y mil veces buen amigo: Cumplo un deber de gratitud al manifestarle lo que le debo por su hermosa, noble y franca respuesta al interrogatorio del Nuevo Mundo: en ella está Vd. retratado de cuerpo entero, con la solidez mental, que se asemeja a la musculatura del espíritu, y con la frescura y rectitud de criterio que han hecho de $\mathrm{V}$, jefe de los conservadores, el más progresivo de nuestros hombres de Estado.

Y esta opinión mía acerca de V. no ha esperado, ni para condensarse, ni para esteriorizarse [sic] a tan grata y venturosa ocasión para mí.

Al primer beneficio siempre se eslabonan otros: dar es obligarse a seguir generoso condimento. Por eso acudo, con respetuosa esperanza, a su amparo,

${ }^{12}$ FUNDACIÓN MAURA. Fondo Antonio Maura, legajo 87. 
en este pleito de la Academia. ¿Quién como Vd. pudiera dejar mentir al ignoto Catalina, que afirma que mi candidatura no será presentada, por falta de tres académicos que firmen la propuesta? Vd. habrá visto que Galdós desea firmarla con Vd. y el tercero es muy fácil de encontrar.

La primer vacante sabemos que es de Besada, y que Vd. firma la propuesta, en la segunda ya no hay más candidato que D. Ricardo León, Catalina imperator $^{13}$ lo ha decretado así.

En estas circunstancias, acudo a V. recordándole, por lo que armoniza con las opiniones que Vd. formuló, el hecho de que, en las Cámaras de Comercio, que dejan senadores, hay mujeres.

No quiero robar a Vd. más precioso tiempo. Lo aguardo todo de esa inteligencia y de ese corazón abierto a lo justo y lo grande, por ley de la naturaleza.

Y soy su amiga por el agradecimiento y su admiradora sería, seré de todos modos, por imposición de mi juicio.

La Condesa de Pardo Bazán.

${ }^{13}$ Se refiere a Mariano Catalina, Secretario entonces de la Academia Española. 
634

MARÍA DEL CARMEN SIMÓN PALMER

bumotr. Dn. Antonio maura

10. $-4-912$

soprenges

Heen Fae

ameigs:

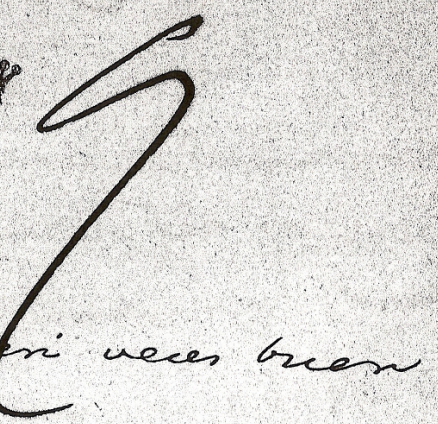

cumplo un deber de gratilin al manutestarce la pue le debo for we hamasa, nobe y tranca reapuerea al witensogatorio del nuevo memos: en ella estat ve. retratar de cuerpo entero, eor la dolidg mental, gue ke asemyas a' la musculatura del sici vili, $y$ con la trescura $y$ rectikit de creiterio sne han kalw der, jefe de los caser varres, el mai krigrentio

RLit, 2008, julio-diciembre, vol. LXX, n. ${ }^{\circ}$ 140, 625-652, ISSN: 0034-849X 
CORRESPONDENCIA DE ANTONIO MAURA CON EMILIA PARDO BAZÁN...

635

Whete

Te suester komber de \& Fas.

y ento

derl no ho esperal, ne hara

aswenase ni har estanoviarse,

a'tan gratay aentivos a das isi hasa me:

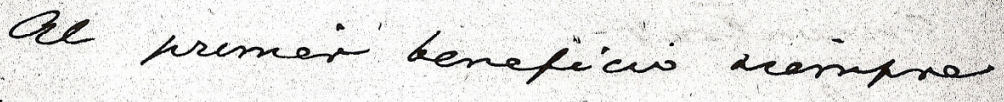
Le eshebaran otsos: char es ofligare a requis ccenst generoso con aumento. Pr ene acess, con vescelaro a es revarys a' lec amparo, en ente pleito de la Ravlemia.

2 Lacent kno lo hadera depai nentir al isnana Cakalina, sue apinma sue

RLit, 2008, julio-diciembre, vol. LXX, n. ${ }^{\circ}$ 140, 625-652, ISSN: 0034-849X 
636

MARÍA DEL CARMEN SIMÓN PALMER

ne cande dalana no keral hresen taba, for Halla de ties acelémios que Kuinen \&a inofuenta? 2r. Kabra' anco que falor derea Kinsarla ase Val. 4 el kencero es muy tacie de encercless.

La krmier vacante sabensed Sue ex Besaba, y que Od. firma la kropuenta: en La degunda ya no ka má Casckitato sue $8 x$. Becarb Leose. batakna siekerakor lo ha dounetialo ane'. In extar circus tasseca. acesi aU, recordandate,

RLit, 2008, julio-diciembre, vol. LXX, n. ${ }^{\circ} 140,625-652$, ISSN: 0034-849X 


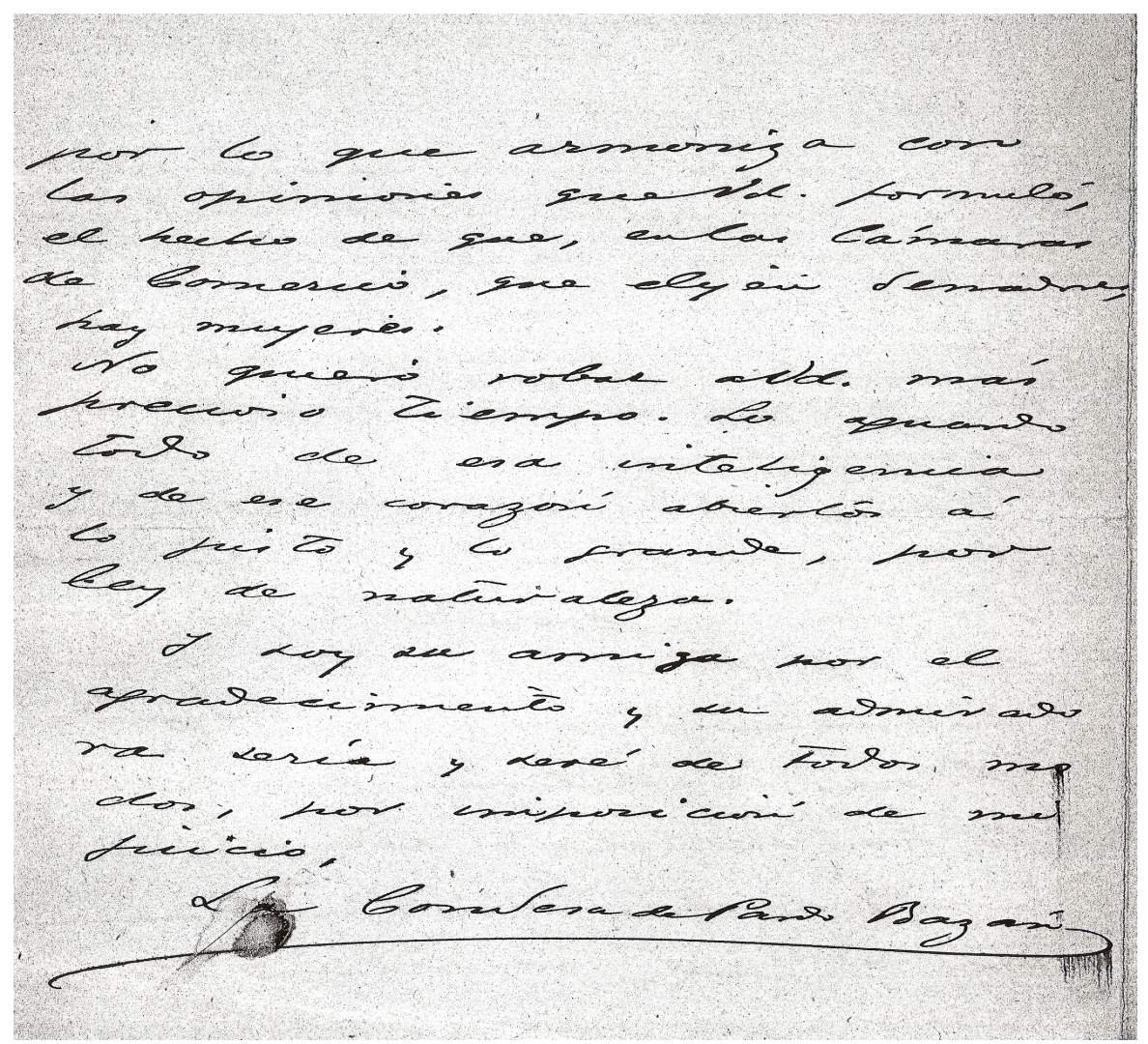

(Carta de luto con iniciales y corona)

Torres de Meirás 20.10.13

Don Antonio Maura

Mi ilustre amigo: No es un favor, sino dos, los que vengo a solicitar de V. El primero, que recomiende al Ministro de la Guerra, de quien depende en absoluto, pues las condiciones están todas llenas, el ascenso a General en la vacante que exista y se abrirá en los primeros días de noviembre, de mi hijo político, el coronel Cavalcante (sic).

Si hubiese podido conseguir su deseo vehemente de ir a África hace unos meses, cuando allí se empezó a complicar de nuevo la situación, él es hombre que hubiese refrescado los aluros de la otra campaña. No pudo ir muy contra su voluntad y por eso no tiene quizás ya el ascenso, para el cual, repito, esta en perfectas condiciones. Y yo, sin preguntarle si hago bien, me dirijo a V. por lograr una intercesión cuya valía salta a la vista y nadie desacatará. 
El segundo favor es... lo de siempre: pero algo creo que pueden haber cambiado las circunstancias. La Academia ha sufrido pérdidas que modifican su contextura interna. Muchos, yo entre ellos, creen que Vd. debe presidirla. Y aun cuando no la presida, porque no quiere, pues otra razón no podrá haber, han desaparecido los reparos que me pareció notar que ataban a V, las manos y la voluntad para que, opinando como opinó, no se resolviese, sin embargo, a presentarme. Y no sigo más, siempre debo esperar mucho de su clara visión de cosas y tiempos.

Con gran respeto y afecto

q.b.s.m.

La Condesa de Pardo Bazán

\section{2}

Excmo. Sr. Don Antonio Maura 26.I.915

Mi ilustre amigo: Al darle las gracias por su amable carta, pido perdón si insisto, pero el asunto lo requiere.

Se está trabajando actualmente para que, en el Supremo, prospere la iniquidad del falseamiento de lo referido al acta de Betanzos.

Parece que la labor es seria, continua y con presiones increíbles.

Acudo a V. pues, como a quien sabe que ésta es una cuestión de las que a V. han inspirado tantas y tantas iniciativas para sanear el aire, que bien lo necesita. Unas líneas de V. para el Presidente, Sr. Ciudad, que tiene por V. tan justo respeto, pudieran ser del mejor efecto, y dejo a su generosa actividad cualquiera otro modo de contrarrestar lo que se está tramando.

No hablo de gratitud, pues de V. como creo me conoce un poco, sabrá que le profeso como dogma.

Es su amiga y admiradora

La Condesa de Pardo Bazán

(Respuesta del Presidente de la Sala de lo Contencioso del Tribunal Supremo 27 enero 1915)

Excmo. Sr. D. Antonio Maura.

Queridísimo amigo y jefe: Puedes asegurar a la Condesa de Pardo Bazán por quién tanto te interesas, que es inexacto en absoluto el rumor de que se hace eco. Puedes también sin riesgo de equivocarte darle otra seguridad, y es la de que en el asunto de que su carta, que te devuelvo, se refiere, ha de obrarse con estricta justicia y sin presiones de nadie, pues aunque alguien quisiese ejercerlas no lograría ningún éxito.

Que viva pues tranquila la Condesa y tenga confianza en los tribunales

Tuyo antiguo y buen amigo

Pepe 
13

(Tarjeta postal con foto suya en la Biblioteca baja de la Torre de Levante. Torres de Meirás)

Torres de Meirás de Betanzos, $\mathrm{P}^{\mathrm{o}}$ de La Coruña 20.6.920

Mi ilustre amigo: la más cordial de las felicitaciones por la gracia que es justicia esta vez, del Toisón

Que lo ostente V. mucho años con salud, como dicen aquí los aldeanos.

$\mathrm{Su}$ amiga afectísima

La Condesa de Pardo Bazán

\section{Cartas de Sofía CASAnOva ${ }^{14}$}

La correspondencia entre Antonio Maura y Sofía Casanova (1861-1958) se inicia en un año nefasto para el político, 1909, porque poco antes se han producido los sucesos que desembocan en la Semana trágica de Barcelona y el fusilamiento de Ferrer Guardia que han provocado su salida del Gobierno. El 19 de noviembre recibe la primera carta de Sofía y, lógicamente, a pesar de los nombres que ella cita como referencia, desea asegurarse de quién es antes de recibirla en su casa, de ahí la nota autógrafa para su secretario (1).

Casanova ha publicado ya esos años siete libros de gran éxito en varios géneros: poesía, relatos de viajes, novelas, y ha colaborado en El Imparcial, La España Artística, o El Liberal por citar sólo algunos periódicos, pero al residir en Polonia es posible que Maura no la conociera. Precisamente en su labor de corresponsal para un semanario polaco desea dejar clara la postura del político español en los recientes acontecimientos, completando así la información que ya ha publicado allí.

Pasan los años sin noticias escritas y en el 1913, Sofía Casanova, gran amiga de Pardo Bazán y gallega como ella, ha conseguido estrenar en el teatro Español, dirigido entonces por Galdós, su única comedia, La madeja, y es ya famosa. Le envía un ejemplar al político de Exóticas y le menciona su intención de presentarlo al premio Fastenrath de la Academia, a la que don Antonio pertenece, y de paso se declara «española fervorosa que no deja de serlo», en alusión a su residencia en Polonia. Maura, como buen diplomático, contesta de un modo ambiguo, seguro de que la Comisión encargada de otorgar el galardón acertará (2). En enero de 1914, Casanova le expresa su agradecimiento por el apoyo prestado para el premio, que ha obtenido, y manifiesta su adhesión «al único gran político español-patriota», a la vez que se lamenta del abandono de quienes antes eran sus amigos (3). La relación entre ambos se estrecha de manera que don Antonio incluso va a asistir a la confe-

${ }^{14}$ Fundación MaURA. Fondo Antonio Maura Montaner, legajo. 25/4. Todas las cartas en un solo folio doblado y escrito por las cuatro caras. 
rencia que Sofía pronuncia en el Ateneo dos meses después sobre la mujer española en el extranjero. Ella, emocionada, le pide un retrato para su famoso salón polaco, que era una embajada no oficial de España en Varsovia. Esta costumbre de regalar los hombres su fotografía era habitual y podemos comprobarlo en muchos archivos de escritores, por ejemplo en el de Rodríguez Marín al que sus amigos le dedicaron muchas, que entonces tenían categoría de obras de arte. (4-5)

La Guerra Mundial, de la que Casanova va a ser corresponsal para el diario $\mathrm{ABC}$ y la ocupación, primero alemana y luego rusa de Polonia, va a impedir en adelante las visitas frecuentes a España, aunque seguirá escribiendo incluso tras perder la vista.

Al presidir de nuevo Maura el gobierno de concentración nacional el año 1921, en el que trata de mantener la neutralidad ante Europa, Sofía no puede resistir el expresarle su temor de que pueda suceder a su país lo mismo que a Polonia (7).

La última noticia está fechada poco antes del fallecimiento de Maura y se trata nada menos que de su solicitud del Premio Nobel, que el duque firmó encabezando la candidatura, porque nuestra autora, con una habilidad extrema, consideró que «no era natural que fuera después de otras, sino la primera», teniendo en cuenta que era el Presidente de la Academia Española.

Princesa 16

19 noviembre 1909

Excmo. Sr. D. Antonio Maura

Mi muy ilustre Señor

Sin otra recomendación que la de servir a mi patria en el extranjero me tomo la libertad de rogar a Vd. una hora de entrevista

El Semanario ilustrado de Varsovia «Juviat» (El Mundo) me ha encargado una serie de artículos sobre todo lo que en España tenga interés general, y me propongo inaugurar la serie de mis trabajos dando a conocer la verdad de la política española y su más alto representante: $\mathrm{Vd}$. señor Maura y los suyos

Durante el verano en el periódico de los nacionalistas polacos (Glos waesawski) hize [sic] una campaña para proclamar de justicia la enérgica conducta del gobierno y reaccionó la opinión Polonia y Rusia, que pensaba y decía de esta horrores e infamias. Aunque ni soy ni seré nunca periodista- pues es mi modesta labor literaria puramente, no quiero dejar de servir mi patria llebando [sic] a la prensa el extremo Norte Europeo la sinceridad de mi pluma.

$\mathrm{He}$ pedido ser presentada a Vd. por cualquiera de nuestros amigos comunes: el Marqués de Valdeiglesias, por ejemplo, o mi paisano Gabino Bugallal (subrayado por el duque), pero eso no amenguaría la molestia que acaso doy 
a Vd. con mi petición, ni he querido que por deferencia a esos señores me conceda Vd. el favor que le pide como española de corazón que de ser hombre estaría incondicionalmente en las filas del partido de $\mathrm{Vd}$.

Quedo suya muy respetuosamente servidora q.s.m.b

Sofía Casanova de Lutoslawski

(Nota en lápiz rojo del duque): «Comprobarlo y citarla una tarde»

14-XI-13

Excmo. Señor don Antonio Maura: Señor mío, tan admirado como estimadísimo: Acaso Vd. no me recuerda y, voy a llamar a su memoria con mi libro, y un ruego atrevido: que lo hojee Vd. si gusta

Algunos amigos míos académicos me animan a presentar Exóticas en demanda del premio Fastenrath y lo hago. Ya comprende Vd. si es de importancia que esas paginas mías — de española fervorosa que no deja de serlosean del agrado de $\mathrm{Vd}$.

Yo que conozco la firmeza, la noble altura del carácter de $\mathrm{Vd}$. no pido a Vd. el favor de su juicio, contrario a sus impresiones de lector.

Pongo en sus manos mi libro como humilde homenaje y deseo de corazón que le sea grato.

Quedo su servidora afectísima q.s.m.b

Sofía Casanova

19 Marqués de Urquijo

(Nota-guía autógrafa del duque a su Secretario): «Gracias -leeré con sumo gusto- Sin duda la Comisión encargada la examinará con las otras obras que concurran inspirándose en el de acertar, etc».

28-I-14

Excmo. Señor don Antonio Maura

Señor mío:

Desde hace días deseo poner a Vd. en dos palabras el testimonio de mi profunda alegría al saber que mis «Exóticas» fueron tan del agrado de Vd. que las concedió su apoyo: Ese hecho, por lo que significa para mi, y por lo que — una vez más - me demuestra de la noble independencia del único gran político español-patriota, ha sido consuelo en el abandono de otros amigos que conocen toda mi labor aquí y fuera de España.

Envío a Vd. los otros libros míos, pobres testimonios de mi gratitud y mi reverencia hacia $\mathrm{Vd}$, esperando que al pasar por ellos la vista halle en ellos 
algo que afirme la buena opinión que he tenido la suerte de merecerle como escritora española. Sincera en sus creencias de fe y patria; adusta a veces con la maldad-ambiente que empequeñece hoy la vida. Quedo de Vd. servidora q.s.m.b

Sofía Casanova Lutoslawski

\section{4}

Exmo. Señor don Antonio Maura

Señor y amigo: Por si quisiera $\mathrm{Vd}$. favorecerme me atrevo a invitarle a la lectura que daré el lunes 16, a las seis de la tarde en el Ateneo. Voy a partir a Varsovia, y desean mis amigos oírme antes. Yo me he resistido hasta el punto de dejar esa lectura, y tener que hacerla un par de días antes de mi marcha. Me daría ánimo la deseada presencia de Vd. y la del Conde de la Mortera y algunas de las encantadoras señoras de la familia de Vd: Perdóneme Vd. el deseo y la súplica, que nacen de mi hondo respeto hacia $\mathrm{Vd}$ y mi afán de ofrecer algo de optimismo a mis pobres versos femeninos y creyentes, a las más nobles almas de mi patria.

Quedo de Vd. ansiosa de probarle mi amistad y admiración su amiga y admiradora q.s.m.b.

Sofía Casanova de Lutoslawska

S/c Marqués de Urquijo 19, 14 marzo 1914

\section{5}

18- III-1914

Excmo. Sr. Don Antonio Maura

Señor y amigo: Dentro de pocas horas salgo para Varsovia —el triste paísy mi gratitud hacia Vd. que honró mi lectura en el Ateneo dándole el alto prestigio de su presencia - me hace volverme a Vd. diciéndole: «Dios quiera que hasta pronto». Dejo siempre España con pena pero me conforta el cumplimiento de sagrados deberes.

¿Quiere Vd. ir a acompañar (mi saloncito España demanda ese favor) la soledad mía con un retrato y una frase? Muy humildemente demando a Vd. esa merced. Tengo por Vd. tan honda estima, tan gran orgullo de ser española, que me atrevo a molestarle y le pido perdón. Suya devotamente amiga q.s.m.b

Sofía Casanova. 


\section{6}

Tarjeta. 9 marzo 1918. «Saluda al patriota su insigne amigo don Antonio Maura y espera de él, reverenciante, la salvación de España» = Petersburgo

Varsovia 6 sept. 1921 Mazzal Kowsk 21

Excmo. Sr. Don Antonio Maura:

Mi señor y amigo: Siguen a Vd. siempre mi pensamiento y mi ferviente amistad, pero no le escribo por miedo de importunarle. Ceso hoy en mi silencio al saber que el patriotismo de $\mathrm{Vd}$. hace nuevo nuevo (sic) acto de $f e y$ de amor a España y a los españoles aceptando las responsabilidades del poder en este grave momento.

Estoy segura que la protección Divina va a dar a $\mathrm{Vd}$. el triunfo que su esfuerzo y su abnegación merecen.

¡España en guerra! Quisiera ir a España y hacer algo ahí por mis soldados pero las circunstancias de este país me encadenan a su ruina.

Dios de a Vd. mi señor y amigo con la sinceridad de sus colaboradores en el Ministerio la victoria de nuestro derecho.

Soy de Vd. constante servidora y admiradora q.s.m.b

Sofía Casanova

Pido al Sagrado Corazón por Vd. su familia y nuestra patria.

\section{8}

[sin fechar]

Exmo Señor Don Antonio Maura:

Mi señor y noble amigo: Me ha traído su carta el más vivo y dulce consuelo al entrar en mi patria ¡Dios pague a Vd. sus buenas palabras! Hágame el favor de decirme cuando puede recibirme pues anhelo ardientemente ver a Vd y a su esposa a quien saludo con gran amistad. Vds. también han tenido penas! Hasta pronto $i$ verdad mi generoso amigo? Respetuosamente q.b.s.m le admira y le está agradecida

Sofía Casanova

s/c Alberto Aguilera 66

Me propongo ir pronto a la Academia a saludar al Sr. Cotarelo que tanto recuerdo 


\section{9}

Exmo Sr. Don Antonio Maura

Mi admirado señor y amigo:

He esperado saber la mejoría de su esposa para pedir a Vd. una entrevista y entregarle mi último libro.

No quiero salir de España sin llevarme la confortable impresión del espíritu de $\mathrm{Vd}$. y de su palabra y le ruego me marque día y hora para tener el gusto de visitarle.

Quedo de Vd. con amistad su afectísima q.b.s.m.

Sofía Casanova

29-III-25

66 Alberto Aguilera

\section{0}

(Tarjeta de visita con membrete impreso) Zofja Lutoslawska (Sofía Casanova) Varsovia Urleza $10 \mathrm{~m} .8$ Madrid Princesa 16

Saluda y le anuncia su visita el miércoles de 7 a 7 1/2 si no recibe recado contrario 31 marzo 25.

\section{1}

1 junio 192566 Alberto Aguilera

Excmo. Sr. Don Antonio Maura

Mi señor y amigo:

Como dije a Vd. cuando tuve el gusto de verle, mis paisanos los escritores y catedráticos gallegos me quieren proponer al premio Nobel con la adjunta demanda, que ruego a $\mathrm{Vd}$. autorice con su noble firma pues no es natural que fuera después de otras, sino la primera

Como en esta semana me voy a Polonia ruego a Vd. me permita enviar mañana a recoger el pliego.

Quedo de Vd. con devota amistad servidora q.s.m.b.

Sofía Casanova 


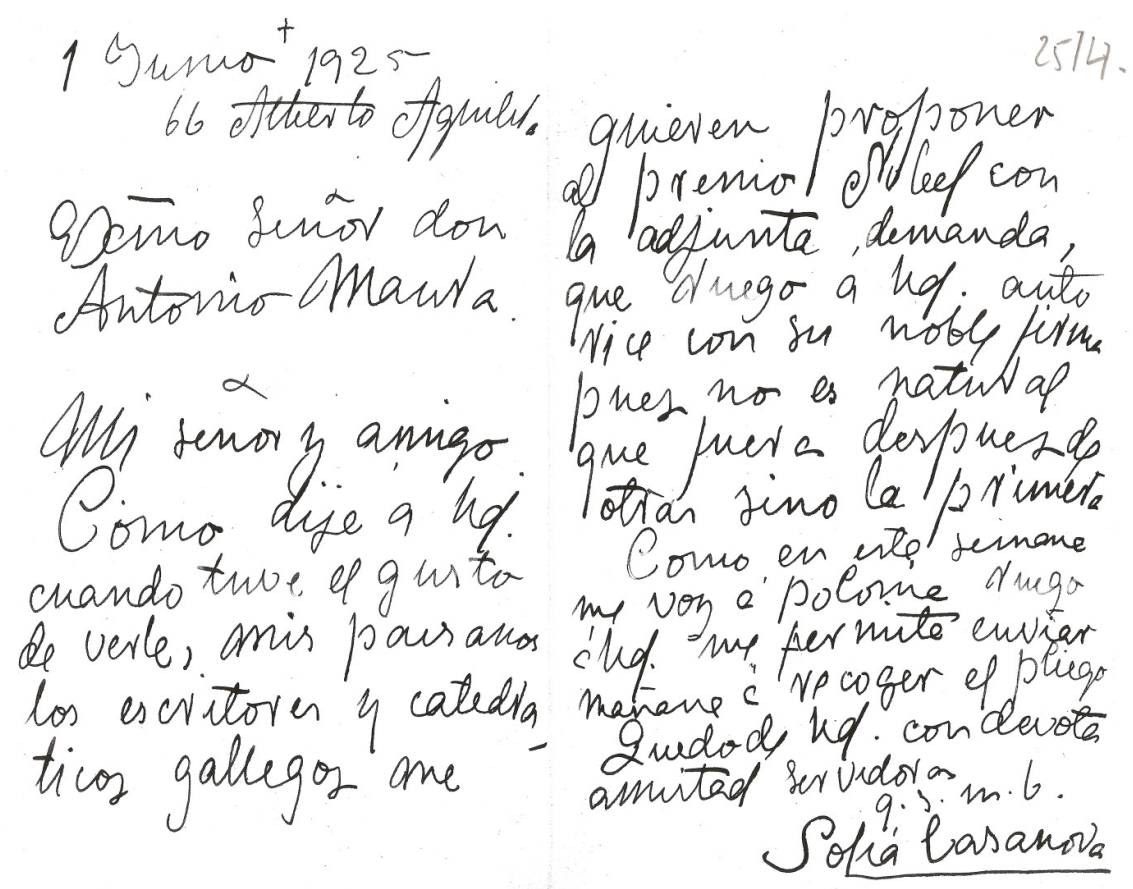

\section{CARTAS DE CONCHA ESPINA}

Al no pertenecer a la aristocracia Concha Espina no puede tener la misma relación de amistad con don Antonio Maura que doña Emilia y en su caso la táctica será la adulación en grado sumo, le considera «noble Ministro de la elocuencia, grande patriota y sutil artista», le declara su afinidad ideológica y le ruega encarecidamente su opinión por escrito sobre sus obras. Sigue así el mismo sistema que Sofía Casanova, primero le envía la obra para que la enjuicie como crítico literario y ante una respuesta, que no podía por menos que ser positiva, dan el paso siguiente: pedirle la recomendación para algún premio.

No deja de tener valor Concha Espina cuando le regala La esfinge maragata, uno de los retratos más duros escritos sobre la situación de las mujeres maragatas y el ambiente de atraso de sus habitantes. Le hace ver su carácter patriótico y social, tanto que considera «maurista» su novela. Ya ese año se cree víctima de una persecución de sus colegas, que han hundido su obra «por ser suya». Es cierto que en los inicios de su carrera le negaron incluso la autoría con distintas atribuciones desde Enrique Menéndez Pelayo a Ricardo 
León ${ }^{15}$. Precisamente éste será el protegido de don Antonio en su entrada en la Academia Española, el año que presenta su candidatura Emilia Pardo Bazán. Pues bien, Concha Espina recurre a la vena sentimental del académico y le expresa, sin mencionar a los cuatro hijos que tiene que sacar adelante, que lleva una existencia «muy oscura a menudo, pobre vida que conoce los más hondos pesares del mundo, vida de luchadora y solitaria donde pocas veces ha salido el sol». Reconoce el padrinazgo de Rodríguez Marín que trata de buscarle alguna ayuda y descubre cómo se documenta minuciosamente y en persona antes de empezar una novela.

En 1918 estrena su obra teatral El Jayón en el teatro Eslava y, de nuevo se lamenta de que a pesar de haber sido «acogida con tan unánime bondad, no duró en cartel tanto como las más furiosamente protestadas, y la retiraron en pleno éxito, a la tercera representación «sin que yo sepa por qué ni pretendo averiguarlo, que solo presentirlo es ya una cosa triste y miserable». Se deshace en elogios al apoyo de Maura, en ese momento jefe de gobierno, y «la importancia consoladora que tiene para mí el hecho de que el gran artista de la palabra, del pensamiento y de las acciones, se haya acordado de mi arte y de mi vida» (4).

La obra se inspiró en un cuento suyo, publicado en 1916 en La Novela Corta de Madrid, y se estrenaba el 9 de diciembre de 1918 por la compañía de Martínez Sierra. No recibe buenas críticas ni la pieza ni los actores y no se mantiene en cartel. En unas declaraciones hechas en 1920 su autora habla de «cosas incalificables ocurridas alrededor del estreno» que consideraba «miserias».

El año 1920 Maura actúa como padrino del enlace de Ricardo León con una joven. Si hacemos caso a alguna malintencionada colega ${ }^{16}$ parece que Concha Espina debió sufrir un duro golpe y emprendió su viaje por América. Podría pensarse que la postura del duque cortaría las relaciones entre ambos, pero prima en ella el sentido práctico y en 1921 le comunica que ha presen-

15 «Cuando vi el éxito de La esfinge Maragata la compré, pero el salto de La Niña de Luzmela a ésta no pudo convencerme. Me dijeron que Enrique Menéndez Pelayo su amante era su autor. Tampoco me convenció. Como Menéndez Pelayo, el mismísimo, no pudo haber escrito aquello tan fuerte y recio a mi ver. La señora Espina menos...». SIMÓN PALMER, María del Carmen, «Los intelectuales españoles a través de la correspondencia de Eva Canel con el Conde de las Navas». Bohemios, raros y olvidados. Homenaje a Federico Canalejas Fustegueras (1876-1914). Cruz Casado, Antonio (coord). Lucena. Córdoba: Diputación de Córdoba, Ayuntamiento de Lucena, 2006. p. 176-77.

16 «Siguió su fama literaria y aquí en La Habana me dijo un montañés que lo que ella escribía estaba revisado por Ricardo León, y que «La esfinge maragata», pedestal de su nombre, era de éste y después me dijeron que había ido con él a Alemania cuando la guerra, pero más tarde vi que Ricardo León se había casado y entonces he solido leer de los dolores, de las amarguras, de las decepciones de Concha Espina, tanto que un no se quien propuso lo del Jardín de Santander para consolarla y de ahí salieron la Gran Cruz y la Banda de María Luisa», en Idem., p. 177. 
tado su obra El Jayón al premio Espinosa de la Academia y se declara «amiga reverente y cordial». La siguiente noticia es la de su gratitud a Maura por el galardón obtenido.

El 23 de mayo de 1923 Concha Espina presenta con una tarjeta a Alfonso Comín, director de la revista Castillos y Leones «defensora de los intereses españoles y americanos», que desea entrevistar a Maura para la revista Excelsior de Méjico e incluirlo como uno de los protagonistas de su libro Figuras de la Raza ${ }^{17}$.

En 1924, la Comisión organizadora del Homenaje de Santander a la escritora le invita «a sumarse espiritual y materialmente» (6) y dos meses antes de fallecer Maura, en septiembre de 1925, se le solicita desde el Ateneo de Santander su adhesión individual y directa al Comité Nobel de Estocolmo para que le sea concedido el Nobel a Concha Espina (7).

1915

Exmo. Sr. Dn. Antonio Maura y Montaner ${ }^{18}$

Ilustre Señor: Fue para mi razón de grande júbilo el que La Esfinge maragata haya retenido siquiera un momento la preciosa atención de V. y animada por la fina carta que me trajo esta nueva, atrévome a expresarle cuánto crecería mi satisfacción y mi gratitud si el noble Ministro de la elocuencia, el grande patriota y sutil artista pudiese hurtar algunos ratos a sus graves ocupaciones y, terminada aquella lectura... me diera su opinión sobre mi libro, hundido por ser mío, pero encaminado con voluntad sincera a un fin patriótico y social, que por las ansias redentoras que entraña bien pudiera llamarse «maurista».

Las devociones ardientes y familiares con que admiro los méritos de $\mathrm{V}$. me impulsan a pedirle este favor, cuya importancia para mis anhelos de artista y de española no me atrevo a ponderar bastante.

Que la mucha bondad de V. conceda gracia y perdón a la solicitud de su admiradora cordialísima que b.s.m.

Concha Espina

c/ Goya 7 Hoy 16 de enero de 1915

${ }^{17}$ FUNDACIÓN MAURA. Fondo Antonio Maura Montaner, Legajo 320.

${ }^{18}$ FUNDACIÓN MAURA. Fondo Antonio Maura Montaner, Legajo 302/2. 
1916

Ecmo Sr. Dn Antonio Maura

Muy ilustre señor y amigo:

Su magnífico retrato y su carta, magnífica también, me han causado una inolvidable emoción. Porque un aplauso y un recuerdo de V. en quien yo venero todas las virtudes y todas las grandezas de la raza, son premio y estímulo que no todos los días amanecen en mi vida, muy oscura a menudo, pobre vida que conoce los más hondos pesares del mundo, vida de luchadora y solitaria donde pocas veces ha salido el sol.

Debo a V. pues una de mis contadas alegrías: gracias por ello con todo el alma. Dudo que el libro, afortunado porque a V. le gusta obtenga algún apoyo eficaz del Estado, por más que de ello se ocupa con cariñoso interés el padrino de la obra nuestro ilustre amigo D. Francisco Rodríguez Marín, y en sus manos dejo esta esperanza.

Salgo esta misma tarde para Córdoba en breve excursión de estudio necesario a la novela que ahora voy a comenzar, y el día 9, Dios mediante, para Comillas donde me tiene V. a su mandato hasta fin de septiembre.

Con profunda devoción y entusiasta afecto se repite de V. ferviente amiga que pide a Dios le colme de de ventura q.b.s.m.

Concha Espina

Viernes-30-6-16

\section{3}

1918

Goya 77

Exmo. Sr Don Antonio Maura

Ilustre y venerable amigo: No acierto a expresarle la alegría, el orgullo que me causó la felicitación de V. con motivo de mi estreno teatral y la importancia consoladora que tiene para mí el hecho de que el gran artista de la palabra, del pensamiento y de las acciones, se haya acordado de mi arte y de mi vida en medio del estrépito glorioso de aquel discurso inolvidable, por el cual se hizo V. acreedor, una vez mas, a la gratitud imperecedera de España $^{19}$.

Mi obra, acogida con tan unánime bondad, no duró en cartel tanto como las más furiosamente protestadas, y la retiraron en pleno éxito, a la tercera representación sin que yo sepa por qué ni pretendo averiguarlo, que solo presentirlo es ya una cosa triste y miserable.

\footnotetext{
${ }^{19}$ Se refiere al discurso de Maura, pronunciado en el Teatro Real en 1915, a favor de la neutralidad española en la Guerra mundial.
} 
Pero de mi intento quedo muy satisfecha, gracias a Dios, muy animada; con el pago, entre los mejores, de tener que agradecer a $\mathrm{V}$. un recuerdo y un favor de la más grande estima para mi.

Que el año venidero sea, para V. y los suyos, una compensación, en lo posible, de los últimos dolores que este les ha tenido, con harta pena de los fervientes amigos de V. y que todas las bendiciones y recompensas le sean concedidas como se lo pide a Dios, su amiga más entusiasta y leal.

Concha Espina

Madrid 21 de dbre 1918

4.

1921

(Carta con orla de luto)

Exmo. Sr. D. Antonio Maura: Mi ilustre y venerado amigo: Me he atrevido a presentar a la Real Academia Española, con opción al premio Espinosa Cortina, mi obra teatral El Jayón ${ }^{20}$ para la que ha tenido tan amables palabras la inmensa bondad de V.

Y me permito aún suplicar al insigne Director de la docta Casa el generoso apoyo de su influencia para mi solicitud si no la juzga desmedida.

Aprovecho de paso esta ocasión para reiterar a V. mi homenaje de adhesión y entusiasmo. Su amiga reverente y leal.

Concha Espina

Goya 77 Madrid 28 de abril de $1921^{21}$

\footnotetext{
${ }^{20}$ Drama en tres actos, estrenado en el teatro Eslava de Madrid el 9 de febrero de 1918.

${ }^{21}$ FundaCión MAURA. Fondo Antonio Maura Montaner, legajo 288/7.
} 
650

MARÍA DEL CARMEN SIMÓN PALMER

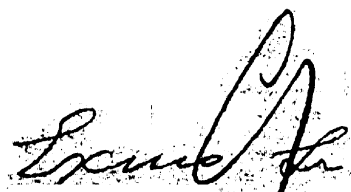

Whi fluthe y neirerato anny The the atienids a farexentor a lor, Stal acadeinia Inpounver

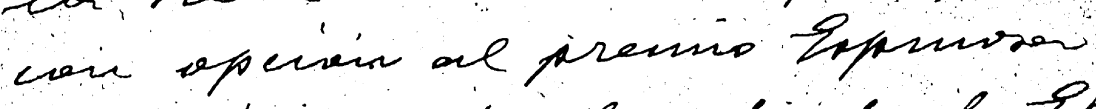
Cortina mi okra tiatrall 2 toufién para la pue ha teribo tom smater polabuar tor immen

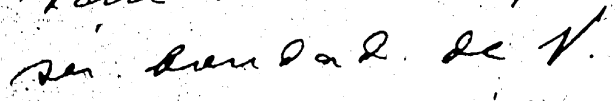

I we persuito ani ruplecoir ol insigive bireatir ki ha bota. Carra el penerove apreyp de in infenencia para in solicitive. síme la fingä desmedila.

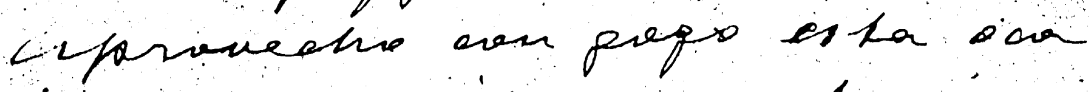
rim para reiterar a I sis

RLit, 2008, julio-diciembre, vol. LXX, n. ${ }^{\circ}$ 140, 625-652, ISSN: 0034-849X 


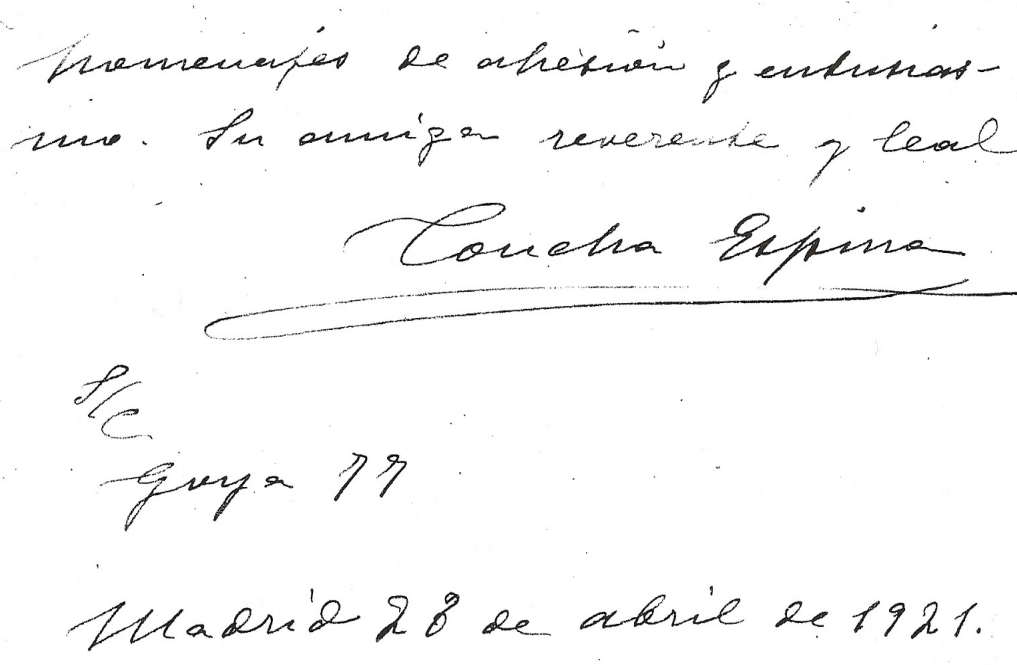

1921

Exmo Sr. Don Antonio Maura

Ilustre señor y amigo admiradísimo: Al hallarme nuevamente favorecida con un premio de la Real Academia Española, se acrecienta de un modo especial mi satisfacción con la gloria de que no me haya faltado al estimadísimo voto de $\mathrm{V}$. mil gracias por el con toda mi alma y toda mi gratitud.

$\mathrm{Y}$ reciba $\mathrm{V}$. con mis homenajes devotos el saludo siempre entusiasta y cordial de su amiga reverente.=Concha Espina

Goya 77 Madrid 16 de junio 1921

\section{6}

1924

Carta con membrete: Comisión organizadora del Homenaje a Concha Espina. Santander»

Ecmo. Sr. D. Antonio Maura:

Los admiradores de la excelsa escritora nos preparamos a rendirle un homenaje, a realizar uno de sus sueños «que la sobreviva el lazo espiritual que con sus novelas labró esta ilustre española, desde su cuna montañesa hasta los confines de los mares». 
Para ello deseamos que en la orilla cantábrica haya unos árboles, unas plantas, una fuente, una vitrina con sus obras como base de biblioteca popular- y un busto suyo que mirando a sus lectores del mundo les sonría con maternal y amorosa gratitud.

¿Quiere V. sumarse al homenaje, espiritual y materialmente?

Por ello le quedará sumamente agradecida= Santander mayo 1924.

(Firman: Carmen de la Vega Montenegro (Profesora de literatura de la Escuela Normal), Policarpo Mingola (profesor de Literatura del instituto Gral y Técnico, José Ñui...(Presidente de la Asociación de la Prensa, Representante del Ateneo de Santander) Evaristo Rodríguez, escritor ${ }^{22}$

\section{7}

Ateneo de Santander septiembre 1925

Sr. D. Antonio Maura y Montenegro

Ilustre Señor:

Lleva un camino tan adelantado y feliz la candidatura de la gran escritora Concha Espina para el Premio Nobel de Literatura que esta Comisión al secundar tan justos propósitos iniciados en las Universidades hispano y norteamericanas, y apoyadas por multitud de firmas prestigiosas desde todas partes del mundo, no puede menos de dirigirse a V. en demanda de la suya, insigne por muchos conceptos y que no debe faltar en esta solemne ocasión, lejos de España a la admirable laureada con los tres premios literarios de la Real Academia Española.

El Comité Nobel prefiere votos individuales, en forma de concisa carta particular como ya la han enviado muchos académicos españoles y extranjeros, sólo con el membrete que les acredite.

Si de esta manera se dignase V. escribir una breve petición a Estocolmo se lo agradeceríamos cordialmente $=$ La Presidente: Carmen de la Vega Montenegro

Dirección del Presidente del Comité Nobel: Herr Prof. Emérito Henrik Schilck Stluregalan 14 Stockholm. Suede

Fecha de recepción 11 de febrero de 2008

Fecha de aceptación: 1 de julio de 2008

${ }^{22}$ FUNDACIÓN MAURA. Fondo Antonio Maura Montaner, legajo 302/2. 